\title{
Coherence and clarity of objectives in doctoral projects
}

DOI:

10.1080/1750399X.2009.10798785

\section{Document Version}

Accepted author manuscript

Link to publication record in Manchester Research Explorer

\section{Citation for published version (APA):}

Olohan, M., \& Baker, M. (2009). Coherence and clarity of objectives in doctoral projects: A research design workshop. Interpreter and Translator Trainer, 3(1), 143-164. https://doi.org/10.1080/1750399X.2009.10798785

\section{Published in:}

Interpreter and Translator Trainer

\section{Citing this paper}

Please note that where the full-text provided on Manchester Research Explorer is the Author Accepted Manuscript or Proof version this may differ from the final Published version. If citing, it is advised that you check and use the publisher's definitive version.

\section{General rights}

Copyright and moral rights for the publications made accessible in the Research Explorer are retained by the authors and/or other copyright owners and it is a condition of accessing publications that users recognise and abide by the legal requirements associated with these rights.

\section{Takedown policy}

If you believe that this document breaches copyright please refer to the University of Manchester's Takedown Procedures [http://man.ac.uk/04Y6Bo] or contact uml.scholarlycommunications@manchester.ac.uk providing relevant details, so we can investigate your claim.

\section{OPEN ACCESS}




\title{
Accepted Author Manuscript
}

Olohan, Maeve and Mona Baker (2009) 'Coherence and Clarity of Objectives in Doctoral Projects', The Interpreter and Translator Trainer 3(1): 143-164.

\section{Coherence and Clarity of Objectives in Doctoral Projects} A Research Design Workshop

\author{
MAEVE OLOHAN \& MONA BAKER \\ University of Manchester, UK
}

\begin{abstract}
Successful supervision of doctoral research is a defining feature and prerequisite to the survival of any research group within the academy. Within translation studies, unlike sociology for instance, relatively few scholars have acquired extensive experience in research supervision, and the discipline as a whole has so far paid little attention to examining the design of research projects at doctoral level. An attempt is made to address this gap by focusing on the design and coherence of doctoral research projects that involve the analysis of translation or interpreting data, drawing on concrete examples of current doctoral projects at the Centre for Translation and Intercultural Studies, University of Manchester. A broad overview of the UK context, in terms of increased monitoring and formalization of research training in recent years, is followed by a detailed discussion and exemplification of design issues in the initial stages of a doctoral project. The paper ends with an outline of a research design workshop for Year 1 and Year 2 students. Although equally valid in many other contexts, the workshop is designed within the context of doctoral study in the UK.
\end{abstract}

Keywords: Coherence, Data, Doctoral training, Qualification descriptors, Quality Assurance Agency, Research design, Research questions.

Higher education in the United Kingdom is subject to monitoring by an independent body known as the Quality Assurance Agency (QAA), which works closely with various government-funded research councils that offer grants to students and staff. One aspect of this monitoring involves ensuring consistent use of qualification titles, for example that undergraduate and postgraduate degrees offered in all universities adhere to the same standards and are of comparable quality. This is done through an initiative known as the Framework for Higher Education Qualifications (FHEQ), first published under the auspices of QAA in 2001. Within England, Wales and Northern Ireland, the Framework for Higher Education Qualifications provides what is known as "qualification descriptors" which "set out the generic outcomes and attributes 
expected for the award of qualifications" (QAA Website $).{ }^{1}$ Qualifications are described predominantly on the basis of achievement of outcomes, not duration of study. The FHEQ is designed to assist higher education providers to maintain academic standards, and the descriptors tend to be referred to explicitly in the development of new programmes and in internal and external audits or reviews of programmes across the UK. ${ }^{2}$ They are also designed to inform international comparability of academic standards.

The FHEQ descriptor for doctoral studies is reproduced in Figure 1. The workshop to be described later in this paper focuses on part of one of the outcomes specified in the FHEQ, namely, "the ability to conceptualise, design and implement a project for the generation of new knowledge, applications or understanding at the forefront of the discipline". We decided to focus on this particular outcome because it underpins all other outcomes specified in the descriptor and because, irrespective of any 'official' descriptors, our experience confirms that successful progression and completion of a doctoral project rests on careful design and conceptualization of its various components from a very early stage. In what follows, we deal only with the conceptualization and design elements and focus on training to be delivered during Year 1 of doctoral studies. However, reflection on and refining of research design is an ongoing process and is encouraged throughout the doctoral programme; the workshop described here can thus also be useful for students in Year 2 of their doctoral studies.

\section{Doctoral degrees are awarded to students who have demonstrated:}

- the creation and interpretation of new knowledge, through original research or other advanced scholarship, of a quality to satisfy peer review, extend the forefront of the discipline, and merit publication

- a systematic acquisition and understanding of a substantial body of knowledge which is at the forefront of an academic discipline or area of professional practice

- the general ability to conceptualise, design and implement a project for the generation of new knowledge, applications or understanding at the forefront of the discipline, and to adjust the project design in the light of unforeseen problems

- a detailed understanding of applicable techniques for research and advanced academic enquiry.

Typically, holders of the qualification will be able to:

- make informed judgements on complex issues in specialist fields, often in the absence of complete data, and be able to communicate their ideas and conclusions clearly and effectively to specialist and non-specialist audiences

- continue to undertake pure and/or applied research and development at an advanced level, contributing substantially to the development of new techniques, ideas, or approaches.

\footnotetext{
${ }^{1}$ See http://www.qaa.ac.uk/academicinfrastructure/fheq/EWNI/default.asp. The framework for qualifications of higher education institutions (HEIs) in Scotland has been developed separately as part of the wider Scottish Credit and Qualifications Framework (SCQF); however, its descriptors for postgraduate qualifications are identical to those of the FHEQ (QAA Website).

2 The 2008 revision of the FHEQ incorporates terminology consistent with the Bologna Process, without altering the qualification descriptors themselves (QAA Website).
} 
And holders will have the:
qualities and transferable skills necessary for employment requiring the exercise
of personal responsibility and largely autonomous initiative in complex and
unpredictable situations, in professional or equivalent environments.

Figure 1: FHEQ doctoral qualification descriptor ${ }^{3}$

The FHEQ differentiates between doctoral degrees awarded on the basis of original research, usually conferred awards of PhD and DPhil, and doctorates which have a substantial taught element, such as professional doctorates, awards whose names usually include the discipline name (DBA, Doctor of Business Administration; EdD, Doctor of Education; EngD, Doctor of Engineering, etc.). A further form of doctoral study is the New Route $\mathrm{PhD}^{\mathrm{TM}}$, also referred to as the integrated $\mathrm{PhD}$. This is a programme with a substantial, assessed, taught element and a comparatively smaller research dissertation.

Most doctorates completed in the field of translation and interpreting studies in the $\mathrm{UK}$ are of the traditional $\mathrm{PhD}$ format, comprising a piece of original research presented and assessed in the form of a thesis (and oral examination); they do not have an assessed taught element. However, in line with the recommendations or stipulations of the UK's research councils, there is now, in all disciplines, a greater awareness of the need for doctoral students to receive research training, described broadly as encompassing "the knowledge, understanding and skills that a student will need to successfully pursue his/her studies, complete a high quality thesis and prepare for a career" (AHRC 2007:22). While the outcome of research training is not summatively assessed, students' training needs are regularly monitored and assessed.

Given that $\mathrm{PhDs}$ are research projects conducted under the supervision of one or more members of academic staff, the Arts and Humanities Research Council (AHRC, the most relevant of the UK research councils to our field of study) recognizes that much of a student's research training will come, informally, through this one-to-one supervision, as well as through formal research training events which might be delivered at a departmental level. A key notion in the ARHC's research training framework is that training should be "tailored to the needs of individual students and their fields of study or research topics" (AHRC 2007:22). The AHRC does not aim to be prescriptive, but sets out core, generic, transferable skills on the one hand and subject-specific knowledge, understanding and skills on the other. The former include, for example, communication, ICT, bibliographical and personal development skills, while the subject-specific component refers to knowledge and understanding of the research context and research methods, among other things.

\footnotetext{
${ }^{3}$ See http://www.qaa.ac.uk/academicinfrastructure/fheq/EWNI/default.asp.
} 
In addition to stipulations by individual research councils, there is also a requirement set out jointly by the UK research councils which groups research skills into (i) research skills and techniques; (ii) research environment; (iii) research management (iv) personal effectiveness; (v) communication skills; (vi) networking and teamworking, and (vii) career management (QAA 2004:34-35). The major challenge that universities face in this context is achieving a balance between training which is tailored to individual students and their fields of study and the economies of scale which may be attained through delivery of training at departmental, school or faculty levels. It is often feasible for training in the more generic skills of (iv) to (vii) above to be delivered to groups of doctoral students from a range of different academic disciplines. While some training in the skills of (i) to (iii) may also be delivered in this way, it is in these areas in particular - research skills and techniques, research environment and research management - that some training at discipline level can be highly effective.

\section{Doctoral training in translation and interpreting studies at Manchester}

Students of translation and interpreting studies at the University of Manchester are required to complete 70 hours of formal training per year, in line with AHRC recommendations. ${ }^{4}$ Research panels are convened twice a year for each individual student to monitor progress of the research project but also to check that appropriate training has been completed. Each academic year begins with the identification of skills training needs through a skills audit that the students complete online. The results of the audit are discussed with supervisors and a training programme is then compiled. This comprises a combination of units from Faculty and School level courses plus training which is specifically tailored to translation and interpreting studies. Examples of the former are Conceptual Skills workshops (dealing with the study of key themes and notions from the humanities) and workshops on mindmapping, organizing conferences, career management, preparing for the viva, etc. The subject-specific training is run by the Centre for Translation and Intercultural Studies (CTIS); it is designed to complement both institutional research training and individual $\mathrm{PhD}$ supervision, to help students to develop as translation scholars and to prepare them for future careers in the field. At the time of writing, the main components of subject-specific training at CTIS are:

- A research design workshop for students in Years 1 and 2 (the focus of this paper, discussed in more detail below)

- An advanced training workshop with a specialist in research training, addressing specific issues which concern researchers in translation and interpreting studies.

- A series of 16 weekly research seminars, in which experienced scholars present their most recent work and discuss it with students.

- A full day of peer presentations, ${ }^{5}$ in which all students present their research projects to their peers, in the presence of all CTIS supervisors, and receive feedback from them.

\footnotetext{
${ }^{4}$ Manchester has approximately 25 doctoral students in translation and interpreting studies at any one time, from many different academic and cultural backgrounds.

${ }^{5}$ The presentations typically take up an entire day (with breaks for refreshments and lunch) because of the large size of the group. Each student is typically allocated ten minutes to present their work, followed by five minutes of discussion. One of the objectives of this event is to provide a forum for
} 
Many of these activities provide opportunities for interaction and critical reflection with leading scholars in the field and foster in students a sense of belonging to a diverse research community whose common goal is to further understanding of translation and interpreting in various modes, media and settings. This development of professional and academic self-confidence is a critical part of preparing researchers for future careers. At earlier stages, however, the Research Design Workshop plays an important role in ensuring that students can embark on a viable research project, having reflected on all aspects of its design and formulation. The next section of this paper discusses the elements of the research project which are addressed in the research design workshop at CTIS. A template for the workshop itself is provided in Appendix 1.

\section{Data and theory in research design}

A research proposal that is viable in principle is an essential first step in any doctoral project, and one that most prospective supervisors insist on receiving prior to accepting an application. The research proposal normally covers the main elements that guide the progression of research and is so important that CTIS supervisors spend the first three months of the student's registration period refining and focusing its various elements. The first research panel held to assess the progression of the student looks specifically at the robustness and coherence of an extensively reworked research proposal.

Practically all research proposals, certainly in our field, feature all of the following elements, though some (like the statement of data) may later be elaborated in more or less detail in the thesis itself, depending on the focus of the project.

- Title

- Rationale

- Detailed research questions

- Theoretical framework

- Research methodology

- Statement of data

- Provisional outline of chapters

Most doctoral theses in translation studies involve the collection and processing of data, though the balance between data analysis and the development of a theoretical model or research methodology may vary from thesis to thesis. In other words, while other areas of the humanities - perhaps like philosophy or theology - may often favour debating conceptual arguments without necessarily collecting and analyzing data (textual or otherwise), doctoral research in translation and interpreting studies has so far required the collection and analysis of (mostly) textual data. We return to the issue of data below; in the meantime, it is important to bear in mind that while both the description of data and the elaboration of a research methodology or a 'novel' theoretical model are important ingredients of doctoral projects, more priority will inevitably be given to one or the other, and this has to be reflected in other elements

new students to meet Year 2 and Year 3 students and for all students to become familiar with each other's research. 
of the thesis, most notably the title, rationale, ${ }^{6}$ research questions and chapter outline. Note that by 'novel' here we do not mean a completely new theoretical model hardly any doctoral student is in a position to 'invent' new theories and, arguably, even the most seasoned of scholars cannot but build on what is already available in the field. Rather, what we mean is that some doctoral students specifically set out to modify an existing theoretical model, for example by addressing a perceived lack of coherence in some part of the model, by extending the model to accommodate new and/or more challenging types of data, or by enriching it with more detail. The latter might include replacing broad or crude categories with more nuanced ones. One example is a current doctoral project at CTIS which attempts to refine and extend Juliane House's model of quality assessment to account for a wider range of shifts in the translation of verbal material as well as shifts in the treatment of non-verbal material in translated multimedial texts such as magazine advertisements (Flippance, in progress).

One of the first decisions that a student is encouraged to make therefore concerns this balance between data description and the elaboration of a new methodology or theoretical model. In the proposed workshop (Task 1B, Appendix 1), we ask participants to produce two versions of their research questions in the first instance: one in which the focus is on providing a detailed analysis of the data they have chosen to work with, and one in which the focus is on developing either a research methodology ${ }^{7}$ or a novel theoretical model of analysis, with the selected data being secondary in importance to that aim. One example which can be discussed with the group (Task 1A, Appendix 1) before they work on their own research questions is outlined here (based on Baldo, in progress).

\footnotetext{
${ }^{6}$ The rationale is where the objectives of the study are outlined, and where the student spells out what he or she considers to be their original contribution to the field.

${ }^{7}$ An excellent example of a doctoral thesis which focused on developing a detailed research methodology is Laviosa-Braithwaite (1996). This proved extremely influential and has since informed numerous other studies in the field.
} 


\section{EXAMPLE 1}

Data for analysis, in both versions: Trilogy of novels by the Italian Canadian writer Nino Ricci: Lives of the Saints (1990), In a Glass House (1993), and Where She Has Gone (1998). Version 1 also envisages analyzing a screen adaptation of the trilogy, a TV film directed by Jerry Ciccoriti (2004).

\section{Research Questions Version 1 (Emphasis on developing a novel model of analysis)}

How are the narrative locations of writers and speakers in diasporic contexts constructed in source texts and their translations into different languages and media?

- What devices do writers and speakers use to position themselves and others, and thus construct their narratives within the context of diasporic writing?

- What happens to these devices in the movement from one language into another and how might translators reconstruct the narrative positions elaborated in the source text?

- What happens to these devices in the movement from one medium (i.e. writing) into another (i.e. film) and how does this impact on the portrayal of narrative positions?

\section{Research Questions Version 2 (Emphasis on data analysis)}

How does codeswitching participate in the narrative construction of ItalianCanadian identity in Nino Ricci’s trilogy and its Italian translation?

- What type of codeswitching occurs in Ricci's trilogy?

- How does codeswitching contribute to focalization and voice in Ricci's trilogy?

- How does codeswitching contribute to plot construction in Ricci's trilogy?

- How is codeswitching rendered in the Italian translation of Ricci's trilogy?

The first version of this proposal suggests that the emphasis will be placed on elaborating a model for describing various devices employed in diasporic writing in general and how these devices are treated in both interlingual and intersemiotic translation. The choice of Nino Ricci's trilogy is secondary to this main focus and its analysis or the analysis of any specific aspect of it is not envisaged as the main contribution of the study. Indeed, almost any other set of data could replace these texts, provided it offers an opportunity to address the research questions, i.e. provided it is an instance of diasporic writing, that it has been translated into the writer's language of origin (in this case Italian), and that it has also been adapted into another medium - a film, radio play, or theatre performance, for instance.

By contrast, the second version of the research questions places the emphasis on the data itself and does not commit the researcher to elaborating a 
novel model of analysis. And precisely because the emphasis here is on the analysis of data, the focus has to be narrowed considerably. Thus, questions relating to the range of 'devices' that communicate a narrative position are replaced by questions focusing on a single textual feature, namely codeswitching, and the issue of screen adaptation (or intersemiotic translation) is discarded. This is one consequence of a change of focus towards data analysis: foregrounding data analysis as the main objective of a doctoral thesis means that a very exhaustive and systematic description of whatever aspect of the data is opted for will be expected. Naturally, no claims can be made or generalizations offered in this case concerning the way in which diasporic writing in general works, hence the removal of any reference to it in version 2.

Once this initial issue of the main focus of the research has been discussed, and each student has decided - at least for the purposes of the workshop - where the focus of their study lies and has a set of provisional research questions that reflect this focus, we move on to discuss the individual elements of the research (or research proposal) in some detail. In particular, we focus on refining the research questions and assessing the robustness and relevance of the data selected for analysis.

\section{Refining the research questions}

It is helpful for both students and those who wish to make use of their research once it is completed to outline an initial, broad research question and then proceed to break it down into specific sub-questions, as can be seen in Example 1 above. In many cases, this breakdown of specific questions can inform the breakdown of chapters. For example, in a thesis entitled Metadiscourse in German History Writing and English Translation: A Study of Interaction between Writers and Readers (Skrandies 2007), the following specific research questions were formulated:

\section{EXAMPLE 2}

1. What linguistic means are used by German historians to present, organize and evaluate their descriptions and narratives about the past?

2. What linguistic patterns and structures are used by these writers to engage with their readers?

3. What other specific rhetorical functions are realized by historiographic metadiscourse?

4. What forms do the translations of metadiscursive patterns take in the target text?

5. What shifts occur in the process of translation of metadiscourse?

6. What are the effects of these shifts in terms of authorial presence and writer-reader interaction?

These questions reflect a division of the data analysis section of the thesis into two distinct parts. Research questions 1-3 were addressed by analyzing patterns of metadiscourse in a corpus of German historiography, with the analysis presented in one chapter. Research questions 4-6 were addressed in a second analytical chapter which focused on the translations of the same body of German history writing.

An initial decision to be made here concerns the choice between an open research question and one that is phrased in the form of a hypothesis or set of hypotheses. At CTIS we generally encourage our students to opt for open research questions that allow them scope for interrogating the data from several perspectives 
and engaging with a range of potentially complex findings that cannot be reduced to the terms of a tightly worded hypothesis. Open research questions have other merits. In particular, they encourage students to keep an open mind about potential areas of interest in the data they are examining, rather than adopt a tunnel vision that restricts them to a single, predetermined aspect of the data. Second, an open research question is less likely to encourage the student to search for a yes or no answer, which means, among other things, that students do not have to panic if the data does not 'oblige' by confirming or refuting an initial hypothesis in such a way as to render the study sufficiently meaningful.

Whether a student opts for an open question or a specific hypothesis, it is important to choose the wording of the question (or hypothesis) very carefully. Almost every word used in a research question sets up specific expectations, some of which a student may not be able or willing to fulfil, as can be seen in the following example.

\section{EXAMPLE 3 (a)}

\section{Research Question (Version 1; emphasis added)}

What role have Arabic translations and rewritings of Edward Said's works played in shaping his impact in Palestine and Egypt?

There are two problems with the wording of this question. First, the word 'impact' suggests that the study will be one of reception, and hence that a suitable research methodology (such as the use of questionnaires or interviews, or the analysis of critical reviews) will be employed. In this particular case, the student had no intention of investigating reception as such and had not thought through the implications of this choice of wording. Second, unless the student intends to use rewriting theory to analyze his data, the wording of this question is misleading. 'Rewriting' is of course a common word which is used in a nontechnical sense in many disciplines. But in translation studies it is strongly associated with the work of André Lefevere and therefore cannot be used in a non-technical sense in a research question.

The above research question was later rephrased as follows (Al-Herthani, in progress); first, to avoid suggesting that the student is embarking on a reception study, and second, to specify the theoretical framework that informs his research:

\section{EXAMPLE 3 (b)}

\section{Research Question (Version 2)}

How has Edward Said been (re)narrated in the Arab World?

This rewording has the additional advantage of opening up the scope of the thesis beyond the analysis of textual material (translations and rewritings), to 
include various agents involved in the process, as can be seen from the breakdown of questions below.

- What institutions (e.g. publishing houses, the academy, the media, the Internet, etc.) participated in (re)narrating Said in the Arab World, and what forms did this narration take?

- What public and meta narratives constrained and/or motivated the process of (re)narrating Said in the Arab World, including Palestine and Egypt?

- Which of Said's works were selected for translation or retranslation, and why?

- What discursive and framing strategies have been used in translating Said's works in Egypt and Palestine? This question focuses on the analysis of paratexts and bindings.

Needless to say, just as the exact wording of a research question or questions is critical in committing the student to a particular type of study and defining its scope, so is the wording of the title. Any changes to the research questions must therefore involve revisiting the title of the thesis. One example will suffice to demonstrate the way in which titles are continually rewritten to reflect increased clarity about the scope and exact aims of the project. The following four titles were adopted at different stages by a CTIS doctoral student who started out with a typically broad question and gradually narrowed it down as she became more confident about what she sees as the main contribution of the study (Boéri, in progress):

\section{EXAMPLE 4}

Initial Research Question: 'What kind of institutions, organizations and groups resort to interpreting in order to function politically in civil society?'

- Title 1: Conference Interpreting and Civil Society Networks

- Title 2: A Narrative Account of the Role of Conference Interpreters in Mediating Dominant and Resistant Discourses

- Title 3: A Narrative Approach to Activist Interpreting, with Particular Reference to Babels and the Alter Globalization Movement

- Title 4: Babels, the Social Forum and the Conference Interpreting Community: Overlapping and Competing Narratives of Activism and Interpreting in the Era of Globalization

Each of the above titles reflects a different focus, as elaborated in more detail in the set of research questions adopted at each stage. Title 1 is much too broad, reflecting a (natural) lack of certainty at this early stage about the exact direction the thesis will eventually take. Title 2 signals the choice of theoretical framework but is not specific about the data to be analyzed. Title 3 finally signals both elements clearly: the choice of theoretical framework and where the data will come from. Title 4 continues in this vein but tips the balance in favour of data analysis: narrative theory is now mentioned in the subtitle rather than the main title, indicating that it is used merely as a tool of analysis and would not be extended or modified as part of the project. 
Tasks 2A-2E in the workshop (Appendix 1) focus on research questions, working on formulating and refining both the overarching research question and the set of concrete or specific sub-questions that come under it. The activities also explore the relationship between research questions and the thesis title and outline of chapters.

\section{Thinking through data-related issues}

Many issues play a role in the selection of data for a particular project. Projects are sometimes designed around data which are considered of interest; in other words, the data may be identified before the researcher has decided on the specific questions to be addressed, the type of verbal or non-verbal features to be analyzed, and the framework(s) of analysis that might prove most useful. Indeed, many research students are initially attracted to doctoral study because of their fascination with a specific set of data (a novel, a writer, a type of interpreting encounter, a series of films, a media event, etc.). Alternatively, a student's interest in pursuing doctoral work may initially be triggered by a broad research question such as 'How do interpreters function in the asylum process?', by a theoretical framework such as relevance theory, or by a specific research methodology such as the use of corpus analysis, with no indication of or specific interest in the type of data he or she might eventually work with. Irrespective of the stage at which a researcher will eventually choose his or her data, the key research skill to be developed is the ability to make coherent links between the research questions, the data, and the analytical and theoretical frameworks, thus ensuring that the data selection is relevant and robust.

Practical considerations which may ultimately influence the research design include availability of data and access to it, as well as the researcher's ability to work with the data. If, for example, it is not possible to obtain permission to record or observe interpreted visits to doctors by patients, then a study of interpreting in that context would have to be designed in such a way as to avoid a reliance on the analysis of the interpretation itself; the study could focus instead on the perceptions or expectations of those using the interpreting services, employing data elicitation methods such as interviews or questionnaires outside of the interpreted encounter itself (e.g. Kaczmarek, in progress). Likewise, the language(s) of the researcher may limit or suggest possibilities. For example, a doctoral student whose languages are English, German and Japanese and who is interested in interpreting in the UK asylum settings must also seek a focus other than the interpreted encounters themselves, in which interpreting between those languages is unlikely to occur. An alternative approach, involving a set of data which is more readily available, is to study the formulation of interpreting policies of different organizations involved in the asylum process to reveal how the roles and activities of interpreters are presented in the institutional discourses on interpreting and how these, in turn, reinforce or challenge dominant social discourse on immigration, multiculturalism, etc. (Maltby, in progress).

A final example of the way in which the availability and nature of data can influence research design may be drawn from doctoral studies which have pursued corpus-based analyses of features of translated language at CTIS, making use of the Translational English Corpus, a readily available in-house corpus of translations into English. ${ }^{8}$ This corpus is designed to include translations only (i.e. no source texts); therefore, its use as a data source requires commitment to a comparable corpus

\footnotetext{
${ }^{8}$ See http://www.llc.manchester.ac.uk/ctis/research/english-corpus/.
} 
methodology, where translated language is compared to non-translated language, or where one set of translations (e.g. by a particular translator) is compared to another set. The data do not lend themselves to use in models of analyses which require comparisons of source text and target text; in studies where research questions address shifts of translation, for example, the researcher would need to construct additional corpus resources which include source texts.

Where the availability of data is not problematic, issues of selection are often a source of difficulty. Students are always required to develop explicit criteria for selecting their data or subsets of it; these criteria need to be relevant to the research questions and research design but, particularly in the context of doctoral studies, may also serve the important function of limiting the scope of the project to something which can be completed in the three-year period. For example, in a study of the translation of conceptual metaphor in popular technology texts, the selection of source and target texts to be studied could be based on date of publication or type of publication, on text type or function, thematic focus of the texts, and so on. Any of these criteria or any combination of them could quite feasibly be used to compile a set of texts from which very substantial quantities of conceptual metaphors and their linguistic realizations in two languages can be extracted; selection criteria are therefore required in this case to produce a set of data which is coherent within the project design but which is also manageable within the scope of the project and for the chosen non-corpus-based method of analysis. The resulting data set might consist of texts from four specific IT magazines, from issues published in 2006 or 2007 only, and could be further restricted to feature articles dealing with specific themes (Papadoudi, in progress).

In Tasks 3A and 3B of the workshop (Appendix 1), emphasis is placed on developing the flexibility to vary the project's focus and research questions in accordance with data choices and vice-versa.

\section{Concluding remarks}

With very few exceptions (e.g. Williams and Chesterman 2002), translation and interpreting scholars have paid little sustained attention to design issues in doctoral research. A small number of publications have engaged with some aspects of doctoral research in the past, including the content of theoretical training in taught $\mathrm{PhD}$ programmes (González-Davies et al. 1998), types of research in the field or those conducted within a specific institution (Bassnett 1998), and questions of time management, topic selection and supervisor-supervisee relations (Gile et al. 2001). In this paper, we attempted to address a specific gap in the literature, focusing on what we see as the most important issue in the early stages of doctoral research. Rather than address individual issues such as topic selection and choice of data separately, we set out to examine the core components of research together and suggest ways in which they can be made to cohere as a set of interdependent parameters. Although these questions can be addressed on a one-to-one basis between supervisor and supervisee, the workshop outlined in the appendix attempts to offer supervisors a template for incorporating the issue of design coherence and robustness within a formal training package delivered to groups of students who can benefit from each other's experience. Given the institutional shift towards greater monitoring and formalized training in various parts of the world, workshops of the type described here should ease the integration of translation and interpreting studies within the broader research environment in the academy. 


\section{MAEVE OLOHAN \& MONA BAKER}

Centre for Translation \& Intercultural Studies, School of Languages, Linguistics \& Cultures, University of Manchester, Oxford Road, Manchester, M13 9PL, UK. maeve.olohan@manchester.ac.uk/mona.baker@manchester.ac.uk

\section{References}

AHRC (2007) Guide for Applicants for Postgraduate Awards in the Arts and Humanities: The Doctoral Awards Scheme, Bristol: Arts and Humanities Research Council. Online: http://www.ahrc.ac.uk/images/Doctoral_guide_2008.pdf (accessed 25 June 2008).

Al-Herthani, Mahmood (in progress) Edward Said in Arabic: Narrativity and Paratextual Framing, Doctoral Thesis, Manchester: Centre for Translation and Intercultural Studies: University of Manchester.

Baldo, Michela (in progress) Translation as Re-Narration in Italian-Canadian Writing: Codeswitching, Focalisation, Voice and Plot in Nino Ricci's Trilogy and Its Italian Translation, Doctoral Thesis, Manchester: Centre for Translation and Intercultural Studies: University of Manchester.

Bassnett, Susan (1998) 'Researching Translation Studies: The Case for Doctoral Research', in Peter Bush and Kirsten Malmkjær (eds) Rimbaud's Rainbow: Literary Translation in Higher Education, Amsterdam \& Philadelphia: John Benjamins, 105-118.

Boéri, Julie (in progress) Babels, the Social Forum and the Conference Interpreting Community: Overlapping and Competing Narratives on Activism and Interpreting in the Era of Globalisation, Doctoral Thesis, Manchester: Centre for Translation and Intercultural Studies: University of Manchester.

Flippance, Vicki (in progress) In Search of a Method for Assessing the Quality of Advertisements in Translation, Doctoral Thesis, Manchester: Centre for Translation and Intercultural Studies: University of Manchester.

Gile, Daniel, Helle V. Dam, Friedel Dubslaff, Bodil Martinsen and Anne Schjoldager (eds) (2001) Getting Started in Interpreting Research: Methodological Reflections, Personal Accounts and Advice for Beginners, Amsterdam: John Benjamins.

González-Davies, María, Richard Samson and Xus Ugarte (1998) 'Course Profile: Doctoral Programme in Translation \& Interpretation', The Translator 4(2): 383-90.

Hermans, Theo (ed.) (2002) Crosscultural Transgressions: Research Models in Translation Studies II, Historical and Ideological Issues, Manchester: St. Jerome.

Kaczmarek, Łukasz (in progress) Developing a Model of Competence in Community Interpreting, Doctoral Thesis, Manchester: Centre for Translation and Intercultural Studies: University of Manchester.

Laviosa-Braithwaite, Sara (1996) The English Comparable Corpus (ECC): A Resource and a Methodology for the Empirical Study of Translation, Unpublished Doctoral Thesis, Manchester: Centre for Translation and Intercultural Studies, UMIST. 
Maltby, Matthew (in progress) Interpreting Policy in Asylum Settings in the UK, Doctoral Thesis, Manchester: Centre for Translation and Intercultural Studies: University of Manchester.

Papadoudi, Dafni (in progress) Conceptual Metaphor in English Popular Technology and Greek Translation, Doctoral Thesis, Manchester: Centre for Translation and Intercultural Studies: University of Manchester.

$Q A A$ website, The Quality Assurance Agency for Higher Education. Online: http://www.qaa.ac.uk/academicinfrastructure/fheq/EWNI/default.asp (accessed 25 June 2008).

QAA (2004) Code of Practice for the Assurance of Academic Quality and Standards in Higher Education. Section 1: Postgraduate Research Programmes, Mansfield: The Quality Assurance Agency for Higher Education. Online http://www.qaa.ac.uk/academicinfrastructure/codeOfPractice/section1/postgra d2004.pdf (accessed 25 June 2008).

Skrandies, Peter (2007) Metadiscourse in German History Writing and English Translation: A Study of Interaction between Writers and Readers, Unpublished Doctoral Thesis, Manchester: Centre for Translation \&and Intercultural Studies, University of Manchester.

Williams, Jenny and Andrew Chesterman (2002) The Map: A Beginner's Guide to Doing Research in Translation Studies, Manchester: St. Jerome. 


\section{Appendix: Research Design Workshop}

\section{PRELIMINARY INFORMATION}

\section{Workshop setup and structure}

This workshop is aimed primarily at Year 1 doctoral students, but Year 2 students are also expected to participate. The activities are designed as collaborative, where small groups of 2-5 students work together on tasks. The examples given in the paper or other known or hypothetical examples can be used for the illustration of individual tasks.

The workshop is envisaged as a full-day event (with breaks for refreshments and lunch), to be run by institutions that have a large body of doctoral students, as is the case with CTIS at the University of Manchester. Institutions with smaller numbers of doctoral students might consider teaming up with other translation studies departments in their region to deliver this workshop or a variant of it to larger groups. The size of the group is an important element of the training, to ensure that students' experience is enriched by exposure to a variety of research topics which are nevertheless subject to the same constraints in terms of design.

The tasks presented below are designed to be student-centred activities, with tutors acting as facilitators but allowing students the freedom to explore and develop ideas collaboratively. Only the student tasks are outlined here; these may be interspersed by tutor-led presentation, group discussion, short student presentations, etc., and tasks may be repeated with other materials or varied in accordance with the availability of examples and the size and composition of groups.

\section{Workshop aims}

To help students to develop:

- the skill to conceptualize and design a research project, focusing in particular on the ability to recognize the implications of different research emphases and to formulate research questions;

- the ability to ensure coherence in the design of a research project, focusing in particular on the relationship between research questions and choice of data.

\section{Intended learning outcomes}

Upon completion of this workshop, students are expected to be able to:

- manage the interplay between data and theory in a particular research project;

- formulate a coherent set of research questions;

- make an informed choice of data in the context of a coherent research design. 


\section{Preparatory reading}

Students are encouraged to read a selection of texts which focus on research design issues before they attend the workshop. These might include the following:

- Crisafulli, Edoardo (2002) 'The Quest for an Eclectic Methodology of Translation Description', in Theo Hermans (ed.) Crosscultural Transgressions: Research Models in Translation Studies II: Historical and Ideological Models, Manchester: St. Jerome, 26-43.

- Tymoczko, Maria (2002) 'Connecting the Two Infinite Orders: Research Methods in Translation Studies', in Theo Hermans (ed.) Crosscultural Transgressions: Research Models in Translation Studies II, Historical and Ideological Issues, Manchester: St. Jerome, 9-25.

- Williams, Jenny and Andrew Chesterman (2002) The Map: A Beginner's Guide to Doing Research in Translation Studies, Manchester: St. Jerome.

\section{WORKSHOP ACTIVITIES}

\section{Part 1: Data and theory in research design}

The aim of these tasks is to sensitize students to the different emphases which a research project can have and the way in which a change in emphasis results in changes in research design, focusing in particular on the interplay between data and theory.

\section{Task 1A}

Description of task: Students are given a short description of some data (as in Example 1 in this paper) and are presented with two sets of research questions, reflecting two different projects in which this data will figure, in different ways (see Note to tutor below). They are asked to analyze the two sets of questions and discuss the differences between a project which foregrounds description of aspects of data and one which foregrounds development/refinement of a theoretical approach. They reflect on the following questions in pairs or small groups and/or discuss with the rest of the group:

- What is the fundamental difference in design between the two projects?

- How is this difference reflected in the formulation of the research questions?

- How is this difference reflected in the scope of data on which the project draws?

Note to tutor: The two sets of research questions given in Example 1 of this paper can be used for this exercise. If alternative examples are used, the first set of research questions should focus on elaborating a model, with data being used to test that model or to demonstrate its applicability. The choice of data is therefore of secondary importance (and could be substituted by another dataset which shares certain relevant characteristics). The second set of questions should be strongly focused on the data itself, i.e. the study should not be designed to generate new models but rather to describe and analyze very specific aspects of this particular dataset. 


\section{Task 1B}

Description of task: Students are asked once again to explore the differences between projects which foreground the analysis of data and projects which foreground the elaboration or refinement of a theory, this time using their own projects as material. For their intended research, they are asked to develop two different research projects and, if possible, formulate a set of research questions for each project. One project should focus on refining the theoretical model they have chosen to work with (or one they are contemplating drawing on, however tentatively) and testing it with their (tentative) set of data, while the other project should focus on studying specific aspects of their dataset. They can make whatever modifications they feel are required in order to produce two projects which have these two different emphases. They carry out this activity in pairs, working together on the design of each project.

Note to tutor: Students work in pairs, i.e. they both work on one student's material, then both work on the second student's material. Students could be paired according to research interests, so that they have some shared knowledge and concerns. Alternatively or additionally, Year 1 students could be paired with Year 2 students.

\section{Part 2: Refining the research questions}

The following tasks aim to make students aware of the need for research questions to reflect the key aims and elements of their research project precisely and to develop students' ability to formulate both overarching and more specific research questions. While practising the formulation of research questions, students also consider the relationship between research questions and the thesis title and chapter outline.

\section{Task 2A}

Description of task: Students are given a thesis title and a set of research questions from a completed $\mathrm{PhD}$ thesis. Based on the research questions, students are asked to produce as comprehensive a description as possible of the research project. They are then asked to evaluate whether the description would be sufficiently informative to figure in a database of thesis abstracts. If not, what information appears to be missing from the research questions and/or the title which makes it difficult to produce a comprehensive summary? They then read the abstract originally produced by the student and explore the relationship between the research questions and the content of the thesis, as summarized in the original abstract. Could the research questions and titles have been formulated more informatively? Does the abstract reveal how the research questions are to be addressed?

Note to tutor: The set of research questions and thesis title from Example 2 in this paper may be used for this exercise. The abstract of that thesis can be accessed at: http://www.llc.manchester.ac.uk/ctis/postgraduate/research/phd-theses/Skrandies/ 


\section{Task 2B}

Description of task: This task explores the link between thesis title and research questions. Students work in pairs. They come prepared with a sheet on which they have written their own provisional research questions. They exchange sets of research questions (formulated without thesis title). Each student tries to formulate a thesis title for their partner's thesis, based on the information they can glean from their research questions. They then discuss the results together, comparing this suggested title to the student's current version, assessing the effectiveness of both titles and identifying possible areas of further refinement of questions which are likely to lead to changes in title in due course. Some general discussion can follow on conventions for thesis titles, with further examples being provided by the tutor.

\section{Task 2C}

Description of task: This is a variation on Task 2B. Instead of suggesting a thesis title, the students suggest a chapter outline for their partner's thesis, based on the research questions with which they have been presented. Students then compare suggestions and explore possible refinements to both research questions and chapter outline. Some general discussion can follow on conventions for structuring theses and additional sample tables of content may be assessed (in conjunction with research questions).

\section{Task 2D}

Description of task: This is a variation on Task 2B. Here, students practise formulating research questions. They receive a set of sub-questions and some details of the research from a fellow student and try to formulate an overarching research question for the project. Students would need to be paired differently from Task 2B. Alternatively, students carry out this task by working in pairs or groups on material from a completed thesis.

\section{Task 2E}

Description of task: Like Task 2D above. Students are given a general, overarching research question and some details about data sources and theoretical approach. They then try to formulate a set of more detailed research questions/sub-questions which could form the basis of a research project. Alternatively, students carry out this task by working in pairs or groups on material from a completed thesis.

\section{Part 3: Thinking through data-related issues}

The aim of these tasks is to sensitize students to the need for data choices to be well motivated and coherent with research aims and research questions. These tasks help students to explore various data selection criteria and to rehearse arguments to support their own data choices. 


\section{Task 3A}

Description of task: A completed or fairly advanced research project is the focus of attention. The tutor or a student presents the main research question or a set of research questions to the group, giving only general information about the data which was used in the research. The students do not have any further information about the project but the person presenting it has in-depth knowledge. It is then the task of the students to find out as much as they can about the data which was used, the options which were considered with regard to data, the choices made, the reasons for the choices made, etc. They do this by asking questions of the presenter but the questions must be formulated so that the answer is 'yes' or 'no' only. This requires students to think about what the likely sources and types of data are, how they might realistically be collected and used, what difficulties there may be in selecting, collecting or analyzing the data, etc., and to refine their questions as they proceed. Each student asks a question in turn. The aim is for the students to find out as much as possible within a certain period of time or within a certain number of questions. Once the time or the allowed questions have elapsed, the group can summarize their acquired knowledge on a board/flipchart and can evaluate whether they have obtained a full and convincing insight into the researcher's data-related deliberations. This task can also be organized as a 'competition' between two groups (finding out about two different projects).

\section{Task 3B}

Description of task: Students work in small groups. They take turns to present their research questions to the group and to tell the rest of the group about the data they intend to work with; if they are already confident of their data, they can say what it is, why and how it is chosen, how it was/will be obtained, how it will be analyzed, etc.; if they are not yet sure what data they can or should use, they can share their deliberations and concerns with the group. The rest of the group has the task of proposing an alternative dataset which could be used in the research project, with the aim of having to make the fewest possible changes to the wording of the research questions. This task places emphasis on the need for a rationale for using one set of data over another and highlights the link between the research design, as reflected in the research questions, and the practicalities of data selection, procurement and analysis. The student whose data is being substituted can argue in favour of their chosen dataset/against their colleagues' proposed changes. Where students have not yet formulated a rationale or made motivated data choices, these issues will be highlighted; the suggestions from their peers may help students to identify more appropriate sources, to refine research questions or to better justify their own choices. The group can work through each student's proposal in turn. 